\title{
Effect of Passivation on the Sintering Behavior of Submicron Nickel Powder Compacts for MLCC Application
}

\author{
Gi-Young Jo, Kwi-Jong Lee ${ }^{a}$, and Suk-Joong L. Kang* \\ Materials Interface Laboratory, Department of Materials Science and Engineering, Korea Advanced Institute of Science \\ and Technology, 373-1, Guseong-dong, Yuseong-gu, Daejeon, 305-701, Republic of Korea \\ ${ }^{a}$ LCR Division, Samsung Electro-Mechanics, Suwon 443-743, Korea
}

(Received December 5, 2013; Accepted December 18, 2013)

\begin{abstract}
During sintering of Ni-electrode multi-layer ceramic capacitors (MLCCs), the Ni electrode often becomes discontinuous because of its lower sintering temperature relative to that of $\mathrm{BaTiO}_{3}$. In an attempt to retard the sintering of $\mathrm{Ni}$, we introduced passivation of the $\mathrm{Ni}$ powder. To find the optimal passivation conditions, a thermogravimetric analysis (TGA) was conducted in air. After passivation at $250^{\circ} \mathrm{C}$ for $11 \mathrm{~h}$ in air, a nickel oxide shell with a thickness of 4$5 \mathrm{~nm}$ was formed on nickel nanoparticles of $180 \mathrm{~nm}$ size. As anticipated, densification of the compacts of the passivated $\mathrm{Ni} / \mathrm{NiO}$ core-shell powder was retarded: the starting temperature of densification increased from $\sim 400^{\circ} \mathrm{C}$ to $\sim 600^{\circ} \mathrm{C}$ in a $97 \mathrm{~N}_{2}-3 \mathrm{H}_{2}$ (vol \%) atmosphere. Grain growth was also retarded during sintering at temperatures of 750 and $1000^{\circ} \mathrm{C}$. When the sintering atmosphere was changed from wet $99.93 \mathrm{~N}_{2}-0.07 \mathrm{H}_{2}$ to wet $99.98 \mathrm{~N}_{2}-0.02 \mathrm{H}_{2}$, the average grain size decreased at the same sintering temperature. The conductivity of the passivated powder sample sintered at $1150^{\circ} \mathrm{C}$ for $8 \mathrm{~h}$ in wet $99.93 \mathrm{~N}_{2}-0.07 \mathrm{H}_{2}$ was measured to be $3.9 \times 10^{4} \mathrm{~S} / \mathrm{cm}$, which is comparable with that, $4.6 \times 10^{4} \mathrm{~S} /$ $\mathrm{cm}$, of the Ni powder compact without passivation. These results demonstrate that passivation of $\mathrm{Ni}$ is a viable means of retarding sintering of a $\mathrm{Ni}$ electrode and hence improving its continuity in the fabrication of $\mathrm{BaTiO}_{3}$-based multi-layer ceramic capacitors.
\end{abstract}

Keywords: Nickel, passivation, densification · grain growth, MLCC

\section{Introduction}

Nickel is widely used as an electrode of multi-layer ceramic capacitors (MLCCs). With miniaturization and increased performance demand of MLCCs, the thicknesses of the $\mathrm{BaTiO}_{3}$ dielectric layer and the Ni electrode layer are respectively now on a submicron scale $[1,2]$. A critical issue that arises with this trend is discontinuity of the Ni electrode layer [3-5]. The reported causes of the electrode discontinuity are the difference in sintering temperature between $\mathrm{BaTiO}_{3}$ and $\mathrm{Ni}$ [4], the difference in the thermal expansion coefficient between the two materials [6], and thermal grooving of the boundaries [7]. As the electrode discontinuity can induce discharge, and also reduces the dielectric capacitance and reliability [8-10], several attempts have been made to suppress densification and grain growth in nano-sized $\mathrm{Ni}$ for MLCC applications. Polotai et al. [11] investigated the effects of $\mathrm{Cr}$ addition. While the continuity of the $\mathrm{Ni}$ electrode was improved, the concentration of oxygen vacancies increased and the leakage current also increased, resulting in deterioration of the dielectric performance. An attempt at modifying the firing rate [12] also yielded similar effects. Lee et al. [13] and Zhang et al. [14] studied the effects of a ceramic coating on $\mathrm{Ni}$ particles. Although the sintering of $\mathrm{Ni}$ powder was retarded with application of the ceramic coating, the conductivity was reduced. Furthermore, insufficient elimination of the organic binder used in the process could also cause deterioration of the electrode properties. As outlined above, the attempts thus far to retard sintering and improve the continuity of Ni electrodes without substantial deteriora-

*Corresponding Author: Suk-Joong L. Kang, TEL: +82-42-350-4113, FAX: +82-42-350-8920, E-mail: sjkang@kaist.ac.kr 
tion of dielectric properties have met only qualified success.

In the present investigation, we studied the effect of passivation of $\mathrm{Ni}$ powder on sintering in an attempt to retard densification and grain growth. As nickel oxide has a much higher sintering temperature than that of $\mathrm{Ni}$ [15], the sintering of $\mathrm{Ni}$ powder is expected to be retarded by its passivation. As $\mathrm{NiO}$ can be reduced at high temperature and no organic binder is used for passivation, the negative effects that arise with ceramic coating of other oxides on Ni powder can be avoided.

A $\mathrm{Ni} / \mathrm{NiO}$ core/shell structured powder was prepared via a simple surface oxidation of Ni powder in air. The sintering behavior of the passivated powder was observed and the electrical conductivity of the powder compacts was measured. It was found that the passivation of $\mathrm{Ni}$ powder is a simple and effective means of retarding densification and grain growth of nano-sized Ni powder. The present results will be applicable to the fabrication of MLCCs with better Ni electrode continuity.

\section{Experimental Procedure}

Samples were prepared from Ni powder of $180 \mathrm{~nm}$ size (NFP 201X, JFE Mineral Ltd., Tokyo, Japan). Optimal passivation conditions, which yield a thin and uniform oxide layer on Ni particles, were determined after a thermogravimetric analysis. When the powder heated to $250^{\circ} \mathrm{C}$ and held at the temperature for 11 hours in air, a uniform and thin $\mathrm{NiO}$ layer was formed on $\mathrm{Ni}$ particles. The passivated powder was observed under a scanning electron microscope (SEM) and a transmission electron microscope (TEM). For TEM observation, the particles were cut into halves using a focused ion beam (FIB) system. The particle size distributions of the non-passivated and the passivated powders were measured using a particle size analyzer (LS 230, Beckman Coulter Co., U.S.A.) in an ethanol medium. The two kinds of powders were lightly pressed in a steel die of $9 \mathrm{~mm}$ diameter and then cold isostatically compressed at $200 \mathrm{MPa}$ to make pellets of $8 \mathrm{~mm}$ diameter and $2.5 \mathrm{~mm}$ thickness. The pellets were sintered at two different temperatures, 750 and $1000^{\circ} \mathrm{C}$, for various times in two different atmospheres, wet $99.93 \mathrm{~N}_{2}-0.07 \mathrm{H}_{2}$ and wet $99.98 \mathrm{~N}_{2}-0.02 \mathrm{H}_{2}$. Fig. 1 plots the variation of the oxygen partial pressure with tempera-

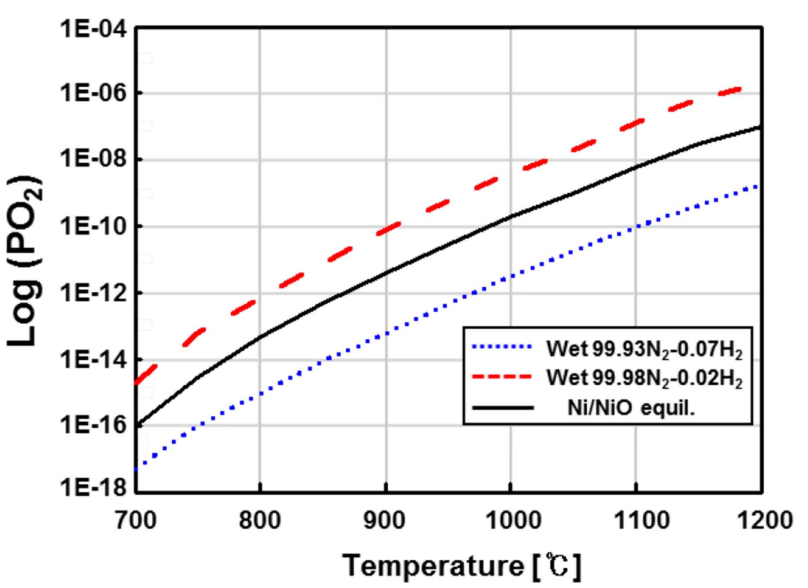

Fig. 1. Variation of the estimated oxygen partial pressure with temperature in different atmospheres.

ture in different atmospheres together with the variation of the equilibrium oxygen partial pressure of $\mathrm{Ni} / \mathrm{NiO}$. Wet $99.93 \mathrm{~N}_{2}-0.07 \mathrm{H}_{2}$ is a lightly reducing atmosphere while wet $99.98 \mathrm{~N}_{2}-0.02 \mathrm{H}_{2}$ is a lightly oxidizing atmosphere. The flow rate of the mixed gas was $150 \mathrm{cc} / \mathrm{min}$. The heating rate was $30^{\circ} \mathrm{C} / \mathrm{min}$. The microstructures of the sintered samples were observed under an SEM after polishing the samples to a $1 \mu \mathrm{m}$ finish and chemical etching in a $60 \mathrm{CH}_{3} \mathrm{COOH}-30 \mathrm{HNO}_{3}-10 \mathrm{H}_{2} \mathrm{O}$ (vol.\%) solution for 2-5 seconds. The average grain size was measured using an image analysis program (Matrox Inspector 2.1). At least 300 grains were examined for the measurement. The electrical conductivity was measured by using a 4-point probe station (11862B, Keithley, U.S.A.).

\section{Results and Discussion}

Fig. 2(a) plots a thermogravimetric curve of nickel powder at a heating rate of $5^{\circ} \mathrm{C} / \mathrm{min}$ in air. It is seen that the weight gain starts at about $250^{\circ} \mathrm{C}$ and increases sharply from about $300^{\circ} \mathrm{C}$. Fig. 2(b) plots the weight gains with annealing time at three different temperatures, 250,300 , and $350^{\circ} \mathrm{C}$. The weight gain is slow and moderate at $250^{\circ} \mathrm{C}$ and becomes rapid at $300^{\circ} \mathrm{C}$, suggesting that the passivation at $250^{\circ} \mathrm{C}$ can be well controlled. Table 1 lists the measured weight changes during passivation at $250^{\circ} \mathrm{C}$ and estimated shell thicknesses. The slower kinetics of passivation in a box furnace compared with that obtained in the thermogravimetric analysis is due to the absence of air flow. To ensure uniform formation of the $\mathrm{NiO}$ layer, we passivated the powder for $11 \mathrm{~h}$. 

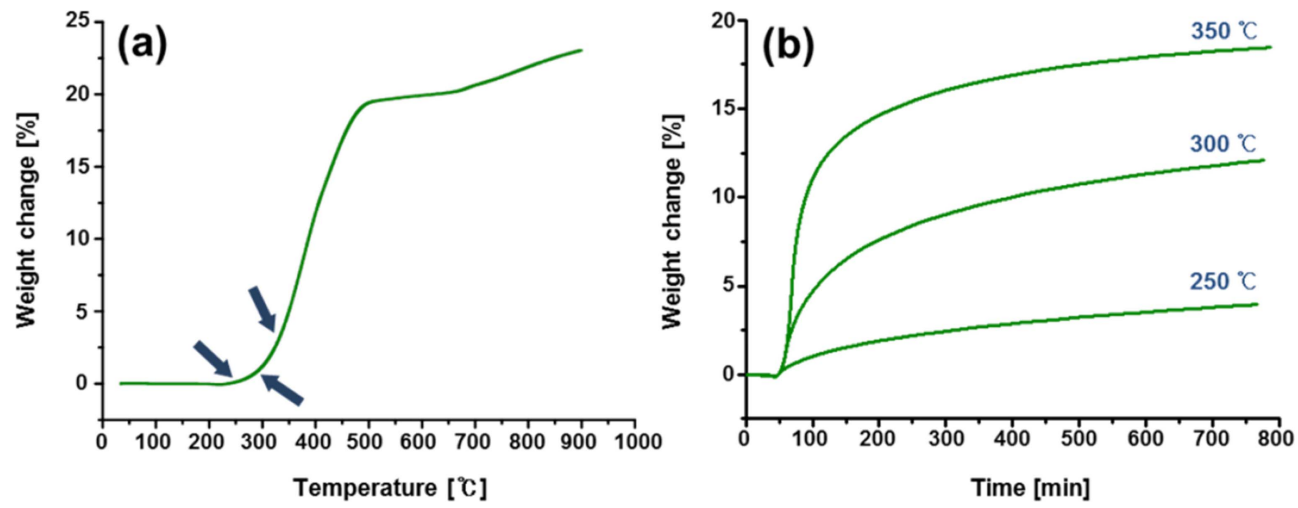

Fig. 2. (a) Thermogravimetric curve of nickel powder at a heating rate of $4^{\circ} \mathrm{C} / \mathrm{min}$ in air. (b) Weight change of nickel powder with annealing time at 250,300 and $350^{\circ} \mathrm{C}$ in air.
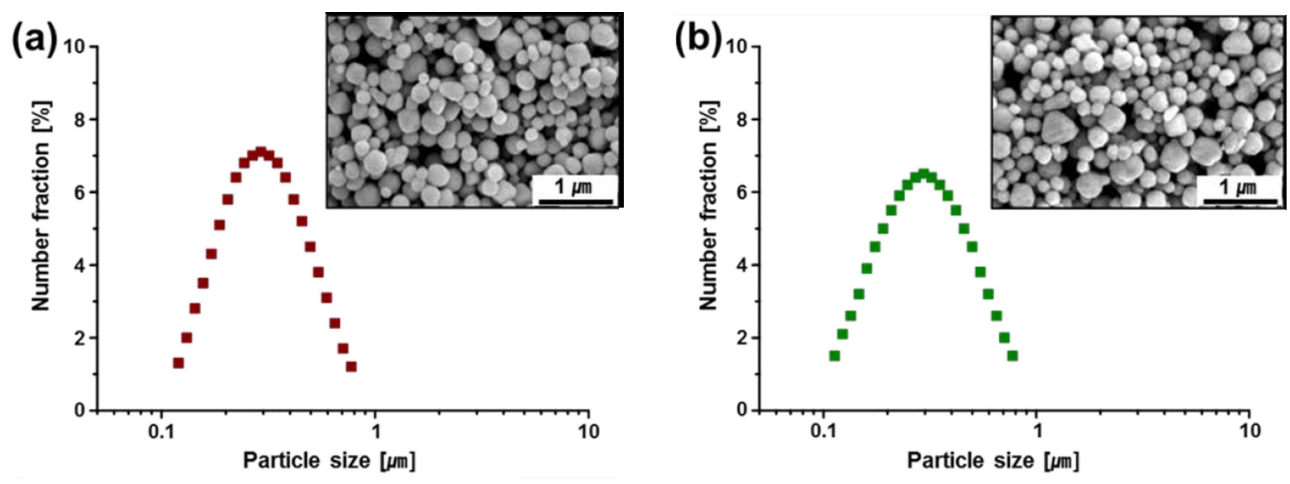

Fig. 3. Size distributions and SEM micrographs of (a) pure nickel powder and (b) passivated nickel powder.

Table 1. Measured weight gain and estimated nickel oxide weight percent and shell thickness of $\mathrm{Ni}$ powder passivated at $250^{\circ} \mathrm{C}$ for various times in air

\begin{tabular}{lclcl}
\hline \hline \multicolumn{1}{c}{ Passivation time } & $2 \mathrm{hr}$ & \multicolumn{1}{c}{$4 \mathrm{hr}$} & $8 \mathrm{hr}$ & $11 \mathrm{hr}$ \\
\hline Weight gain [\%] & 0.18 & 0.65 & 0.75 & 1.1 \\
NiO [wt\%] & 0.81 & 3.0 & 3.46 & 5.04 \\
Shell thickness [nm] & 0.73 & 2.71 & 3.12 & 4.57 \\
\hline
\end{tabular}

After the passivation, the average size and size distribution of the powder were nearly the same, as shown in Figs. 3(a) and 3(b). An x-ray analysis, which is not shown here, revealed the presence of oxide in the passivated powder. Indeed, a thin and quite uniform oxide layer of 4-5 $\mathrm{nm}$ thickness formed at the surface of each particle, as shown in the HRTEM micrograph in Fig. 4.
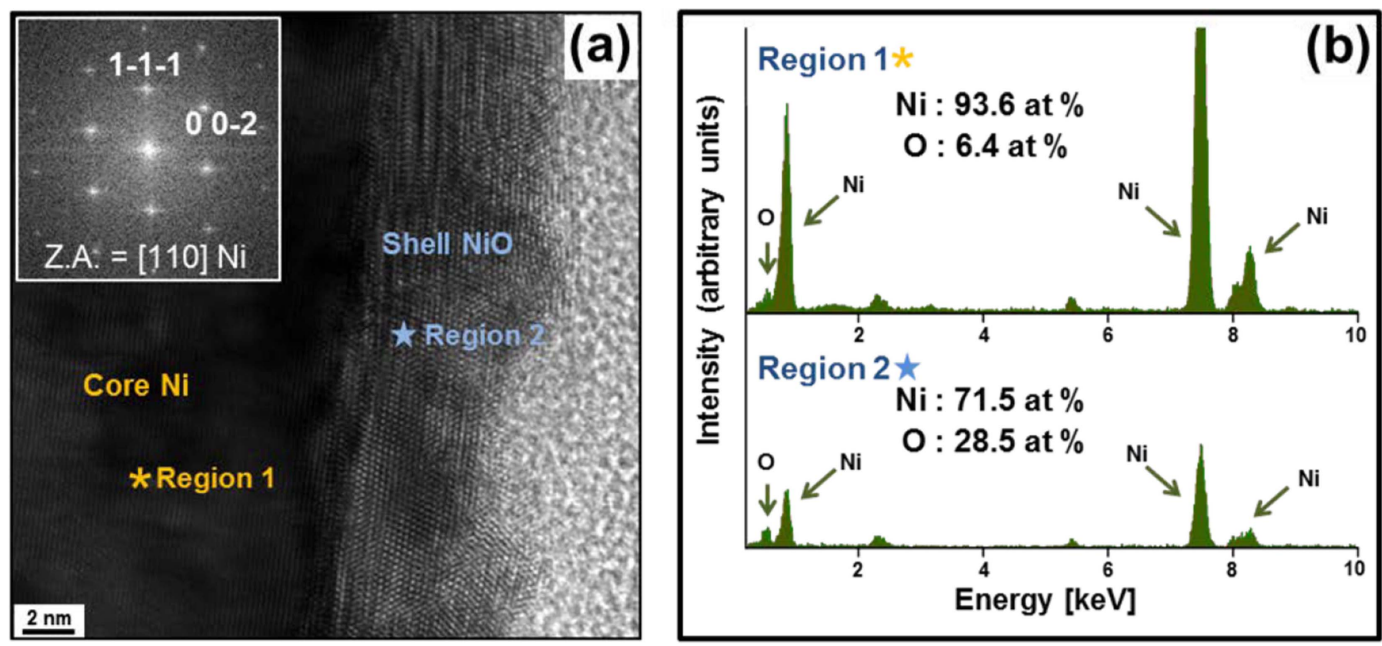

Fig. 4. (a) HRTEM micrograph of nickel powder passivated at $250^{\circ} \mathrm{C}$ for 11 hours in air. (b) EDS spectra of region 1 and 2 in (a). 
Between the oxide layer and the core, there are no macroscopic flaws, indicating that the oxide layer covers the nickel core well $(\mathrm{Ni} / \mathrm{NiO})$. The observed thickness is similar to the estimated shell thickness from the weight gain of Ni powder (Table 1). Fig. 4(b) shows the EDS (energydispersive $\mathrm{x}$-ray spectroscopy) analysis data of a $\mathrm{Ni} / \mathrm{NiO}$ core/shell structured particle. A small amount of oxygen is also detected in the Ni core because of the presence of

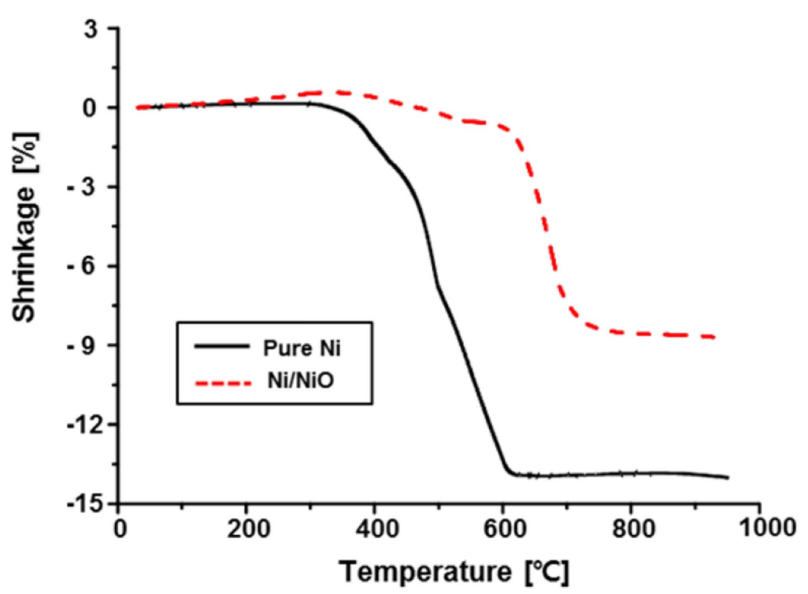

Fig. 5. Shrinkage curves of pure $\mathrm{Ni}$ and $\mathrm{Ni} / \mathrm{NiO}$ compacts as a function of sintering temperature at a heating rate of $10^{\circ} \mathrm{C} /$ min. an oxide layer at the surface of the backside hemisphere of the particle.

Fig. 5 plots dilatometric curves of pure $\mathrm{Ni}$ and $\mathrm{Ni} / \mathrm{NiO}$ powder compacts during heating at $10^{\circ} \mathrm{C} / \mathrm{min}$ as a function of temperature. It is seen that densification of the pure $\mathrm{Ni}$ powder compact starts at about $400^{\circ} \mathrm{C}$, as reported previously [4]. On the other hand, the onset temperature of shrinkage of the passivated powder compact is increased to $630^{\circ} \mathrm{C}$. This is ascribed to slower diffusion of atoms in the passivated oxide layer. When the $\mathrm{Ni}$ / $\mathrm{NiO}$ powder compact was heated to $950^{\circ} \mathrm{C}$ at $10^{\circ} \mathrm{C} / \mathrm{min}$, the shrinkage is less than $9 \%$, while it is $\sim 14 \%$ for the pure Ni powder compact. This suppressing effect of the oxide layer is comparable to that of a coated layer of other oxides on $\mathrm{Ni}$ [14], thus indicating that the introduced passivation step is a simple and effective means of suppressing densification of the $\mathrm{Ni}$ electrode layer during the production of MLCCs.

Fig. 6 shows SEM micrographs of pure $\mathrm{Ni}$ and $\mathrm{Ni} / \mathrm{NiO}$ powder compacts sintered at two temperatures, 750 and $1000^{\circ} \mathrm{C}$, for $1 \mathrm{~h}$ in wet $99.93 \mathrm{~N}_{2}-0.07 \mathrm{H}_{2}$. At both 750 and $1000^{\circ} \mathrm{C}$, the grain size of the pure $\mathrm{Ni}$ powder compact is approximately 20-30 $\mu \mathrm{m}$, as shown in Figs. 6(a) and
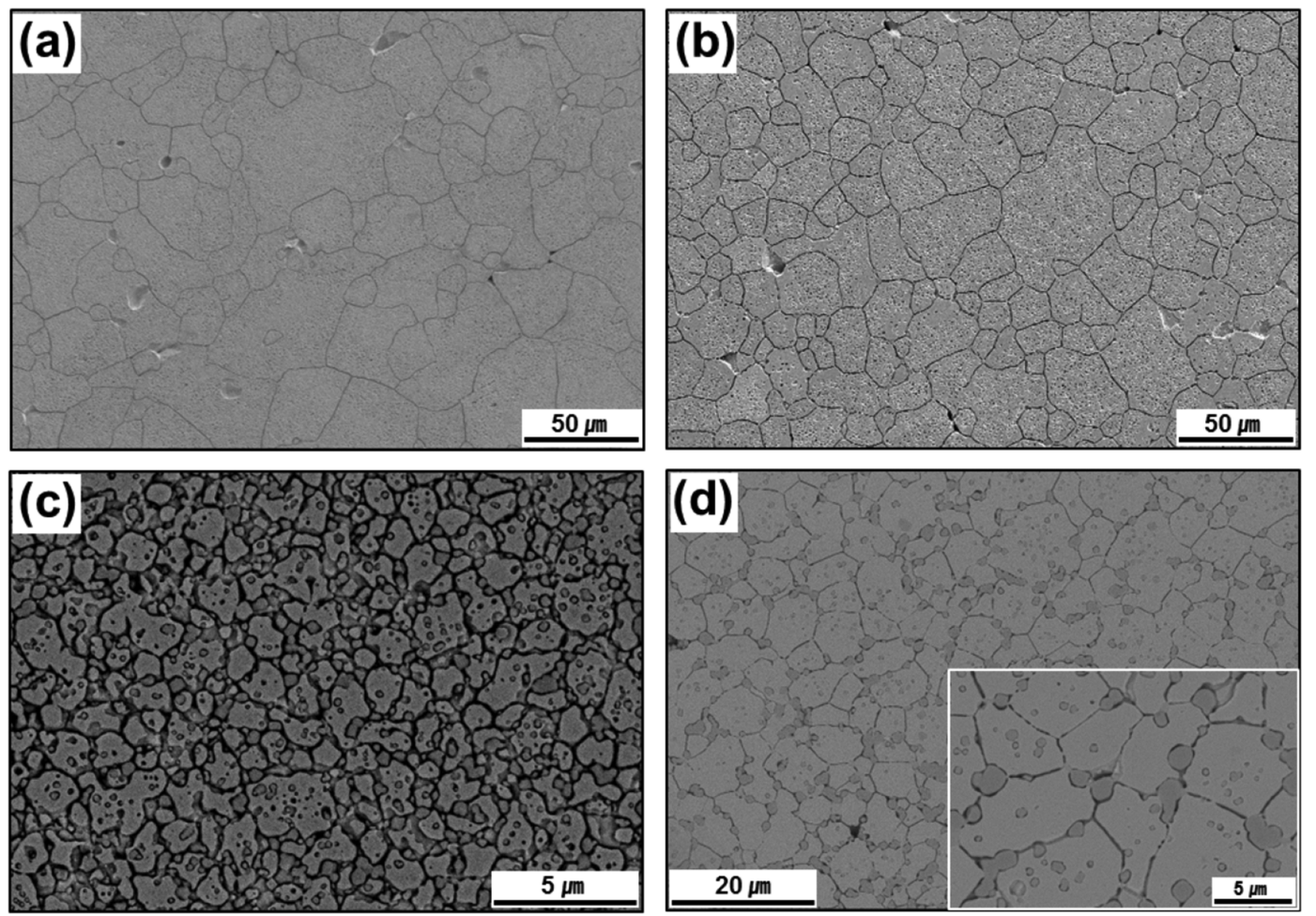

Fig. 6. SEM micrographs of pure nickel ((a) and (b)) and $\mathrm{Ni} / \mathrm{NiO}\left((\mathrm{c})\right.$ and (d)) powder compacts sintered at $750^{\circ} \mathrm{C}((\mathrm{a})$ and $(\mathrm{c}))$ and $1000^{\circ} \mathrm{C}\left((\mathrm{b})\right.$ and (d)) for 1 hour in wet $99.93 \mathrm{~N}_{2}-0.07 \mathrm{H}_{2}$. The back-scattered $\mathrm{SEM}$ image in the inset in (d) reveals the presence of $\mathrm{NiO}$ particles (dark regions) in $\mathrm{Ni}$ matrix (grey regions). 

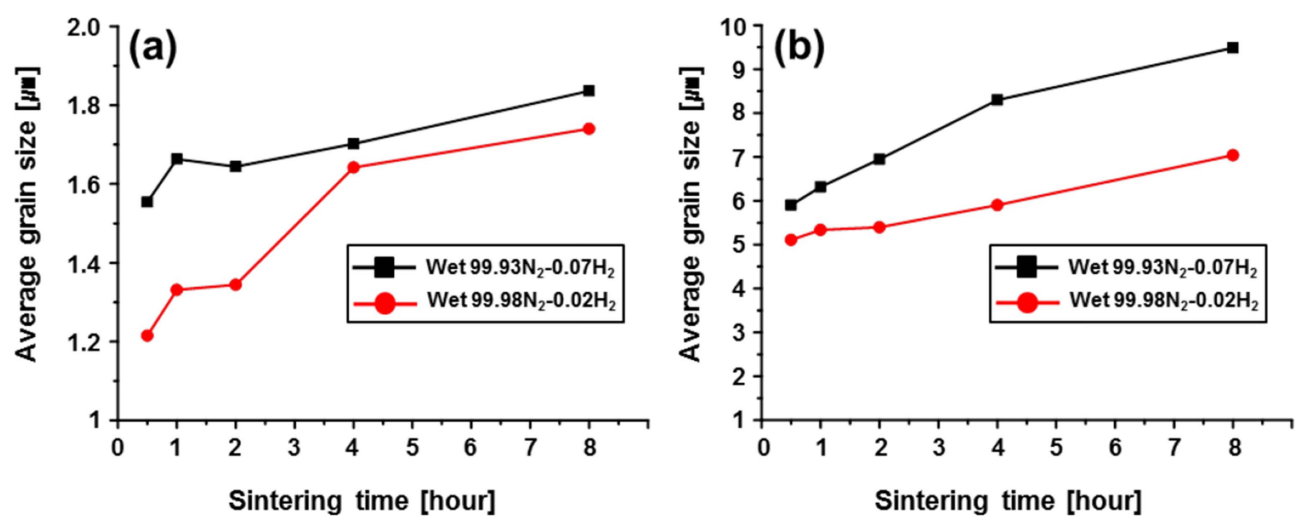

Fig. 7. Average grain size of $\mathrm{Ni} / \mathrm{NiO}$ samples with sintering time at (a) 750 and (b) $1000^{\circ} \mathrm{C}$ in two different atmospheres.

6(b). Considering the initial powder size of $180 \mathrm{~nm}$, the grain growth during sintering of $\mathrm{Ni}$ is dramatic. According to a previous study [16], the coarse microstructure of 20-30 $\mu \mathrm{m}$ grain size is a result of the formation and the impingement of abnormal grains that occur at low temperature. In contrast, grain growth in a compact of passivated powder was significantly suppressed, as shown in Figs. 6(c) and 6(d).

Fig. 7 plots the variation of the average grain size of $\mathrm{Ni}$ in $\mathrm{Ni} / \mathrm{NiO}$ powder compacts with sintering time at 750 and $1000^{\circ} \mathrm{C}$ in slightly oxidizing (wet $99.98 \mathrm{~N}_{2}-0.02 \mathrm{H}_{2}$ ) and the slightly reducing (wet $99.93 \mathrm{~N}_{2}-0.07 \mathrm{H}_{2}$ ) atmospheres, respectively. In general, the average grain size in wet $99.98 \mathrm{~N}_{2}-0.02 \mathrm{H}_{2}$ is smaller than that in wet $99.93 \mathrm{~N}_{2}$ $0.07 \mathrm{H}_{2}$. In both cases, however, the average grain sizes of $1-2 \mu \mathrm{m}$ at $750^{\circ} \mathrm{C}$ and of $5-7 \mu \mathrm{m}$ at $1000^{\circ} \mathrm{C}$ for sintering time of $1 \mathrm{~h}$ are much smaller than that of $\sim 30 \mu \mathrm{m}$ for pure Ni powder compacts. This remarkable suppression of grain growth in the $\mathrm{Ni} / \mathrm{NiO}$ powder compact is attributed to the suppression of sintering and also the drag of $\mathrm{NiO}$ particles against the boundary movement [17]. It seems that $\mathrm{NiO}$ particles formed with agglomeration of unreduced $\mathrm{NiO}$, which was remained due to insufficient reduction in a slightly reducing atmosphere.

Table 2 lists the electrical conductivity measured by the four-point probe technique at room temperature for pure

Table 2. Electrical conductivity of pure $\mathrm{Ni}$ and $\mathrm{Ni} / \mathrm{NiO}$ compacts sintered for 8 hours in wet $99.93 \mathrm{~N}_{2}-0.07 \mathrm{H}_{2}$

\begin{tabular}{ccc}
\hline \hline Sintering temperature & $1000^{\circ} \mathrm{C}$ & $1150^{\circ} \mathrm{C}$ \\
\hline Pure Ni & 4.2 & 4.6 \\
$\mathrm{Ni} / \mathrm{NiO}$ & 3.1 & 3.9 \\
\hline
\end{tabular}

$\left[\times 10^{4} \mathrm{Scm}^{-1}\right]$
$\mathrm{Ni}$ and $\mathrm{Ni} / \mathrm{NiO}$ powder compacts after sintering at 1000 and $1150^{\circ} \mathrm{C}$ for $8 \mathrm{~h}$ in wet $99.93 \mathrm{~N}_{2}-0.07 \mathrm{H}_{2}$. Although $\mathrm{NiO}$ particles remained at the grain boundaries in the sintered $\mathrm{Ni} / \mathrm{NiO}$ samples, the electrical conductivity of the $\mathrm{Ni} / \mathrm{NiO}$ compacts is comparable to that of the pure $\mathrm{Ni}$ powder compact. According to a previous study [14], the electrical conductivity $\left(2.2 \times 10^{6} / \Omega / \mathrm{m}\right)$ of sintered compacts of Ni powder coated with other oxides is substantially inferior to that $\left(4.9 \times 10^{6} / \Omega / \mathrm{m}\right)$ of sintered pure $\mathrm{Ni}$ compacts. The good conductivity of our passivated $\mathrm{Ni}$ powder compacts is due to reduction of the oxidized layer and spherodization of remaining oxides during sintering. It is therefore concluded that the passivation of nickel powder is a good solution to reduce the sinterability of Ni for application of Ni electrodes in MLCCs.

\section{Conclusions}

In fabricating MLCCs, retardation of sintering of the Ni electrode is critical in order to improve the continuity of the electrode layer. As the sintering temperature of $\mathrm{NiO}$ is higher than that of $\mathrm{Ni}$, Ni powder was passivated in an attempt to suppress its sintering in the present study. Ni powder with an oxide layer of 4-5 nm thickness was prepared after conducting a thermogravimetric analysis. Densification of the passivated Ni powder was retarded and grain growth was also suppressed. The electrical conductivity of the passivated and sintered Ni powder was comparable with that of the unpassivated and sintered Ni powder. It is concluded that the passivation of Ni powder is a simple and useful way of retarding sintering and hence improving the continuity of $\mathrm{Ni}$ electrodes without significant reduction of their electrical conductiv- 
ity in MLCC production.

\section{Acknowledgements}

This work was supported by Samsung Electro-Mechanics Co. Ltd. through the Center of Advanced MLCC Manufacturing Processes and also by the Priority Research Centers Program (No. 2012-048034) through the NRF funded by MEST, Korea.

\section{References}

[1] H. Kishi, Y. Mizuno and H. Chazono: Jpn. J. Appl. Phys., 42 (2003) 1 .

[2] C. A. Randall: J. Ceram. Soc. Jpn., 109 (2001) S2.

[3] B. Y. Yu and W. C. J. Wei: J. Am. Ceram. Soc., 88 (2005) 2328.

[4] A. V. Polotai, G. Y. Yang, E. C. Dickey and C. A. Randall: J. Am. Ceram. Soc., 90 (2007) 3811.

[5] Z. Yan, O. Guillon, S. Wang, C. L. Martin, C. S. Lee and D. Bouvard: Appl. Phys. Lett., 100 (2012)263107.
[6] T. Cheng and R. Raj: J. Am. Ceram. Soc., 72 (1989) 1649.

[7] R. Dannenberg, E. A. Stach, J. R. Groza and B. J. Dresser: Thin Solid Films, 370 (2000) 54.

[8] J. Yamamatsu, N. Kawano, T. Arashi, A. Sato, Y. Nakano and T. Nomura: J. Power Sources, 60 (1996) 199.

[9] M. M. Samantaray, A. Gurav, E. C. Dickey and C. A. Randall: J. Am. Ceram. Soc., 95 (2012) 257.

[10] M. M. Samantaray, A. Gurav, E. C. Dickey and C. A. Randall: J. Am. Ceram. Soc., 95 (2012) 264.

[11] A. V. Polotai, T. H. Jeong, G. Y. Yang, E. C. Dickey, C. A. Randall, P. Pinceloup and A. S. Gurav: J. Electroceram., 18 (2007) 261.

[12] M. M. Samantaray, K. Kaneda, W. Qu, E. C. Dickey and C. A. Randall: J. Am. Ceram. Soc., 95 (2012) 992.

[13] J. Y. Lee, J. H. Lee, S. H. Hong, Y. K. Lee and J. Y. Choi: Adv. Mater., 15 (2003) 1655.

[14] Y. Zhang, X. Wang, J. Y. Kim, J. R. Kim, K. H. Hur and L. Li: J. Am. Ceram. Soc., 96 (2013) 2163.

[15] I. Yoshio: J. Am. Ceram. Soc., 41 (1958) 397.

[16] S. H. Jung, D. Y. Yoon and S.-J. L. Kang: Acta Mater., 61 (2013) 5685.

[17] S.-J. L. Kang: Sintering : Densification, Grain Growth \& Microstructure, Elsevier, Oxford (2005) 95. 